Max-Planck-Institut für demografische Forschung

Max Planck Institute for Demographic Research

Doberaner Strasse 114 - D-18057 Rostock - GERMANY

Tel +49 (0) 3812081 - 0; Fax +49 (0) 3812081 - 202;

http://www.demogr.mpg.de

MPIDR WORKING PAPER WP 2002-051

NOVEMBER 2002

\title{
Wealth and Cohort Size: \\ Stock Market Boom or Bust Ahead?
}

\author{
Christian Helmenstein \\ Alexia Prskawetz (fuernkranz@ demogr.mpg.de) \\ Yuri Yegorov
}

(c) Copyright is held by the authors.

Working papers of the Max Planck Institute for Demographic Research receive only limited review.

Views or opinions expressed in working papers are attributable to the authors and do not necessarily reflect those of the Institute. 


\title{
Wealth and Cohort Size: Stock Market Boom or Bust Ahead?*
}

\author{
Christian Helmenstein ${ }^{\dagger}$ \\ Alexia Prskawetz ${ }^{\ddagger}$ \\ Yuri Yegorov ${ }^{\S}$
}

November 13, 2002

\begin{abstract}
Intersecting the life-cycle pattern of savings accumulation with the wealth distribution, this paper studies the impact of heterogeneity in cohort size on the allocation of assets held by private households. Based on a closed form solution to a theoretical model, the results do not lend support to the hypothesis that stock markets are doomed to suffer from a meltdown as the baby-boom cohort retires. Instead, various demographic and economic factors may contribute to attenuate an expected stock market decline. Depending on the shape of the aggregate wealth distribution, the allegedly negative stock market impact of population ageing may even be offset or reversed. On the other hand, contrary to previous work a decline in stock market prices may set in well before collective retirement.
\end{abstract}

JEL classification: D31, G12, J11

Keywords: Wealth Distribution, Asset Prices, Demographic Heterogeneity, Stock Market Meltdown Hypothesis

${ }^{*}$ This paper was written in part while Christian Helmenstein and Yuri Yegorov were visiting the Max Planck Institute for Demographic Research in March 2002. The authors are grateful for comments and suggestions by Thomas Lindh.

${ }^{\dagger}$ IHS Institute for Advanced Studies, Vienna and ESCE Economic and Social Research Center, Cologne and Eisenstadt.

${ }^{\ddagger}$ Max Planck Institute for Demographic Research, Rostock, Germany. Corresponding author. The views expressed in this paper are the author's views and do not necessarily reflect those of the Max Planck Institute for Demographic Research.

$\S$ Central European University, Budapest, Hungary and IHS Institute for Advanced Studies, Vienna, Austria. 


\section{Introduction}

In an influential empirical paper on the financial market implications of demographic change, Poterba (1998) advanced the so-called 'asset market meltdown hypothesis'. According to this hypothesis, the clustered retirement of comparatively large cohorts ('the baby-boomers') may cause a stock market crash, pursuant to a stock market boom stemming from highly synchronous peak saving behavior.

In the same vein, in an overlapping generations context Abel (2001), Brooks $(2000)^{1}$, Constantinides, Donaldson and Mehra (2000) argue that the (expected) price of capital rises above its steady state level during the baby boom, just to revert during the baby bust below the steady state level. ${ }^{2}$

This paper challenges the notion of an asset market meltdown as a consequence of population ageing. While previous work suggested an attenuating effect of international stock market integration (Schieber and Shoven, 1994) and possibly of social security (Abel, 2002), ageing is hypothesized to be the main driving force that determines the allocation of assets between stock and bond holdings. From the life-cycle risk aversion hypothesis which holds that an individual investor's relative risk aversion increases with age (both from a cross-sectional and a time-sequential perspective) it follows that, ceteris paribus, as a population ages aggregate asset demand will shift away from stocks in favor of bonds (Jagannathan and Kocherlakota, 1996), necessitating sufficiently high market risk premia to restore equilibrium. ${ }^{3}$ The difficulties associated with establishing robust empirical results in this strand of research, led Poterba (2001, p. 582) to state that "Most measures of demographic structure, however, do not show a statistically significant correlation with asset returns."

The role of the wealth distribution of private households in the allocation of assets between stock and bond holdings has not been taken into account so far, however. ${ }^{4}$ If stock holdings relative to bond holdings increase with wealth, and

\footnotetext{
${ }^{1}$ Brooks (2000) considers per-period returns rather than the price of capital, that is, the current yield of assets displays a pro-cyclical pattern as the age wave, in this case defined as the population change relative to the parent cohort, advances.

${ }^{2}$ See Mankiw and Weil (1989) as well as Bakshi and Chen (1994) for the impact of differences in cohort size on US housing prices. A thorough review on demographic structure and asset returns can be found in Poterba (2001).

${ }^{3}$ On the empirical side, contrary to the results reported by Bakshi and Chen (1994) for the US, average age does not appear to have forecasting power for risk premiums in international data. Rather changes in the proportion of retired persons seem to be a significant predictor (Ang and Maddaloni, 2001).

${ }^{4}$ For reasons of keeping the technical apparatus at the indispensable minimum, we simplify the universe of asset categories ,commonly accepted to stipulate "wealth" (cf. Wolff, 1995, for several definitions of household wealth), to consist of merely two assets, viz. stocks and bonds.
} 
if dissaving during retirement is negatively correlated with wealth, the financial market consequences of population ageing may be far from obvious.

Incorporating observation-based empirical specifications, the paper aims to provide a closed form solution to a theoretical model. It draws upon concepts deriving from demography such as cohort size as well as finance such as portfolio decision making and asset market clearing that are embedded in a framework of macroeconomic reasoning.

The paper is organized as follows. The next section presents stylized facts about heterogeneity in cohort size and wealth. Section 3 introduces the divergent dynamics of wealth accumulation for high-wealth and low-wealth individuals, on the basis of which section 4 provides formulas for the aggregate demand for assets and the market equilibrium. In section 5 the price dynamics of stocks and bonds over time are derived for a benchmark model of constant cohort size. Allowing for heterogeneous cohort size, section 6 constitutes a fully-fledged model with analytically tractable asset market equilibrium conditions. The case of wealth heterogeneity across high wealth individuals is considered in section 7. Calibration and simulation of analytical results is presented in section 8. Concluding remarks and avenues for future research are summarized in section 9 .

\section{Stylized Facts}

Inspection of data for Germany and the United States reveals various relevant stylized facts.

1. The post-war baby boom in Germany started around 1955 and lasted until 1966 (Birg, 2001, p. 53). The annual number of births increased from 820,000 up to $1,050,000$ during this period (Figure 1.a). Figure 1.b illustrates the propagation of the baby boom generation through time as well as that of two additional troughs and one hump. ${ }^{5}$

Insert Figure 1 here.

2. Stock holdings are highly concentrated on high-wealth households. According to the capital taxes statistics (Federal Statistical Office, 1995) as compiled by the German Federal Statistical Office, the upper four percentiles

\footnotetext{
${ }^{5}$ The troughs around age 20 and between age 45 and age 50 for the year 1960 may be explained by the loss of births during the second and first world war, respectively, while the hump between age 25 through age 30 for 1960 is caused by the high birth figures preceding the second world war.
} 
Table 1: Aggregate Savings Rate in Germany According to Age

\begin{tabular}{|c|c|c|c|c|c|c|c|}
\hline Age & $<25$ & $25-34$ & $35-44$ & $45-54$ & $55-64$ & $65-69$ & $\geq 70$ \\
\hline $\begin{array}{c}\text { Savings } \\
\text { Rate \% }\end{array}$ & 8.9 & 14.2 & 15.1 & 15.3 & 10.3 & 2.7 & 6.2 \\
\hline
\end{tabular}

Basis: Household Net Income. Source: Income and Expenditure Survey (Federal Statistical Office, 1998), p. 90, own calculations.(For considerations about sample properties such as accuracy, representativeness, coverage, and comparability of the Income and Expenditure Survey cf. Börsch-Supan and Essig, 2002.)

of the wealth distribution own $56.7 \%$ of all corporate stockholdings in Germany. This observation supports the hypothesis that the propensity to hold stocks is an increasing function of wealth. ${ }^{6}$

3. From a cross-sectional perspective, for Germany the aggregate savings rate is approximately constant between $10 \%$ and $15 \%$ during working age (2060 , cf. Table 1), reaching a maximum between the age of 45 and 54. Albeit decreasing sharply upon retirement, the aggregate savings rate remains positive, even at its minimum for the age bracket between ages 65 and 69 (see Börsch-Supan, 2002, on the German savings puzzle).

Given the elementary life-cycle hypothesis of savings accumulation and deaccumulation, such an outcome would be unlikely if there were only one type of individual, leaving aside behavioral enhancements such as habit persistence and precautionary saving.

If, by contrast, individuals differ in their wealth, the median income individual may indeed be a net dissaver during retirement, the average stock owner may be a net saver even during retirement, however. Since the behavior of the average stock owner rather than that of the median saver is determining the excess demand for stocks, it follows that previous work resting on the assumption of aggregate net dissaving of stocks (that is, negative excess demand of stocks) by the baby boom retirees may be built on ambiguous empirical ground.

4. By implication, sizable fractions of wealth (especially in the upper wealth percentiles and thus particularly in the form of stocks) are bequeathed rather

\footnotetext{
${ }^{6}$ See Börsch-Supan and Essig (2002) for a more detailed analysis on stockholding in Germany, and Gollier (2001).
} 
than consumed. ${ }^{7}$ This stylized fact holds although the absolute nominal value of securities sold is increasing with age while households remain net savers (Federal Statistical Office, 1998, p. 90). ${ }^{8}$

5. Empirical analysis supports the notion of a highly time-invariant wealth distribution. To exemplify, despite considerable discretionary tax- and social security-related re-distributional endeavor, the share of total assets held by households in the uppermost quintile of the US (disposable) income distribution amounted to $62,6 \%$ in 1998, compared to 61, $5 \%$ in 1989 (Maki and Palumbo, 2001). ${ }^{9}$

Substantial asset price volatility notwithstanding, the feature of rigidness carries through even to the level of individual asset categories. The share of the uppermost quintile in publicly traded corporate equity, for instance, reached $83,1 \%$ in 1998 while at $81,1 \%$ in $1989 .{ }^{10}$

\section{Individual Path of Wealth Accumulation}

\subsection{Asset Allocation}

The investment universe consists of bonds and stocks. ${ }^{11}$ Individual wealth can be allocated across these two assets.

Wealth accrues from two different sources, viz. bequests and savings, and is additionally augmented by the returns from stocks and bonds. Savings are ac-

\footnotetext{
${ }^{7}$ To illustrate, consider the share of purchased plots of land as compared to inherited plots. In the bracket between 25-34 (35-44) years of age $45 \%$ (58\%) of the assets (in terms of their number) are acquired either through bequest or bestowal, the latter being equivalent to a bequest brought forward. A further interesting discussion on the role of intra-family transfers in fostering social inequality is given by Szydlik (2002). Empirical results on intergenerational transfers in Germany are summarized in Lüth (2001). Data of the Income and Expenditure Survey and the SocioEconomic Panel evidence that 'transfers inter vivos are fairly concentrated, positively related with donor's economic status, and in the majority of cases directed from old to young' (Lüth, 2001, p. 57). Moreover, '... bequests are much more concentrated than transfers inter vivos, ...'(Lüth, 2001, p. 57).

${ }^{8}$ Calculated as geometric average, the increase amounts to about 1,6\% p.a.

${ }^{9}$ Figures as measured by the triennial Survey of Consumer Finances from 1989 through 1998. See also Rodriguez, Diaz-Gimenez, Quadrini, and Rios-Rull (2002) for a most recent update on the US wealth distribution.

${ }^{10}$ The rather small differences observed in the cross-sectional - albeit - income distribution even between market-based and the former centrally-planned economies further corroborate this assumption (Atkinson, 1995).

${ }^{11}$ For that matter, the variable bonds represents a risk-free, interest-bearing class of assets, or money.
} 
cumulated as a constant fraction of wage income, as stipulated by the constant savings rate $s$.

Due to capital accumulation as a result of an on-going issuing activity of firms (through the payment of stock dividends), in the context of a Cobb-Douglas-type production function, wages $w(t)$ grow exponentially. With constant fractions of capital and labor in aggregate output it follows that as long as the capital/laborratio $^{12}$ is kept constant, wage growth is proportional to the rate of the issuing activity of firms, $r_{S}$, which in turn is equal to economic growth. ${ }^{13}$

The number of bonds in circulation at $t=0$ is $F(0)=\bar{F}$, while the number of stocks issued at $t=0$ is $S(0)=\bar{S}$. The annualized nominal return on bonds is $r_{F}$. The number of bonds outstanding evolves according to $F(t+1)=F(t)(1+$ $\left.r_{S}\right)$ which implies balanced growth with a constant public debt to GDP ratio. Analogously, stocks yield annual dividends in the form of stock dividends, such that for any time $t$, we have $S(t+1)=S(t)\left(1+r_{S}\right)$, where $r_{S}$ denotes the return on stocks. ${ }^{14}$ This specification ensures that price changes, both of bonds and stocks, are not due to economic growth but are solely determined by demographic dynamics whose specific influence can thus be identified.

The amount of accumulated wealth $V(a, t)$ at age $a$ and time $t$ defines the asset allocation in the individual portfolio at age $a$. Assuming that the degree of risk aversion is decreasing in wealth but increasing in age, the following formulae for $P$ denoting the share of wealth invested in stocks applies: ${ }^{15}$

$$
P(a, t)=\frac{V(a, t)}{C+V(a, t)+\mu a}
$$

with $C, \mu$ being constants. For $V(a, t)$ sufficiently high, $P(a, t)$ asymptotically approaches 1 , conforming to the observation (second stylized fact) that the upper income decile holds the major part of its wealth in stocks.

\footnotetext{
${ }^{12}$ We measure labor in terms of efficiency units to reflect human capital accumulation.

${ }^{13}$ The macroeconomic framework is described in more detail in Appendix 1.

${ }^{14}$ Taking into account the idiosyncratic risk associated with investing in the stock of individual firms, the dynamics of the number of stocks outstanding may more precisely be stated as $S(t+1)=$ $S(t)\left(1+E r_{S}\right)$ where $E r_{S}$ denotes the expected return on stocks. Even though this kind of risk can be diversified away, since other kinds of risk persist $r_{S}$ may be referred to as certainty equivalent.

${ }^{15}$ For a rigorous treatment of the optimal portfolio choice with respect to investor risk preferences, given the distribution of wealth, cf. Gollier (2001). Empirically, net worth appears to have a positive effect on the share of risky assets, for example in Italy, the Netherlands, and the United States, cf. Kapteyn and Panis (2002).
} 


\subsection{Two Types of Individuals: High-Wealth and Low-Wealth}

In line with the third stylized fact, instead of an egalitarian wealth distribution across individuals, consider a wealth distribution across individuals resting on two different realizations of per-capita wealth.

We split each cohort in two groups that hold approximately the same aggregate wealth. This implies that the size of these groups will differ markedly with highwealth individuals constituting a relatively small fraction of total population, a property that accurately mimics the second stylized fact.

Conforming to the fifth stylized fact, the fraction of high and low-wealth people respectively is assumed to be the same for all cohorts, ${ }^{16}$ while the population size of cohorts may differ. For simplicity, we assume cohort-specific but otherwise identical wealth within each age group for low and high-wealth individuals.

The size of the birth cohort born at time $t-a$ is equal to $B(t-a)$. Assuming zero mortality until age 80 with all individuals dying at exact age 80 and no migration the density of the population at time $t$ and age $0 \leq a \leq 80$ is equal to $f(t, a)=B(t-a)$. In each cohort, a fraction $\sigma$ of all individuals has high wealth while a fraction $1-\sigma$ has low wealth with $0<\sigma<<1$. Hence, at time $t$ there will be $\sigma B(t-a)$ high-wealth individuals of age $a$ and $(1-\sigma) B(t-a)$ low-wealth individuals of age $a$.

Wealth dynamics of high-wealth individuals as a function of age. High-wealth individuals are assumed to start their independent economic activity at age 20 . We assume that a high-wealth person that is born at $t-a$ will inherit a particular wealth at age 20 and at time $t-a+20$ which we denote by $V_{r}(20, t-a+20)$. Furthermore we assume that high-wealth individuals hold all their wealth in stocks. For simplicity we assume that high-wealth individuals spend all labor income on consumption while all capital income is reinvested in stocks. We assume that wealthy people work up to the end of their life so that they will always have an income from which to live off. The wealth of each high-wealth individual at time $t$ and age $a \geq 20$ is given by

$$
V_{r}(a, t)=V_{r}(20, t-a+20) e^{r_{S}(a-20)}
$$

with $V_{r}(20, t-a+20)$ denoting the inherited wealth of cohort $t-a$ at age 20 .

The procedure of wealth inheritance. We denote the initial age specific wealth schedule of high-wealth individuals at time $t=0$ by $V_{r}(a, 0)=\rho(a)$. While every

\footnotetext{
${ }^{16}$ The assumption of a constant wealth distribution across time may be further justified by the fact that from an individual point of view, savings of low-wealth people are not irrelevant but from a macro perspective these savings have a negligible effect on the wealth distribution.
} 
cohort of high-wealth individuals accumulates wealth exponentially by holding stocks, some assumption has to be added about the inheritance procedure in order to close the model. We simply assume that all generations at age 80 pass their wealth to the newborn generation of age 20 . Under this specific bequest procedure we need to assume that the wealth of high-wealth individuals is identical across ages. ${ }^{17}$ We will employ this mathematically consistent assumption in the first version of our model. It leads to the following wealth distribution which only depends on time:

$$
V_{r}(a, t)=V_{r}(0,0) e^{r_{S} t}
$$

A more general assumption about the wealth distribution of high-wealth individuals relies on the formula

$$
V_{r}(a, t)=V_{r}(0,0) e^{r_{S} t} \rho(a)
$$

where $\rho^{\prime}(a)>0$. A consistent bequest schedule that would not violate the afore mentioned assumption of wealth being an increasing function of age, $\rho(a)$, would be if bequests are spread uniformly across offspring of different age. Alternatively, the presence of inter vivos transfers would be in compliance with this assumption.

Wealth dynamics of low-wealth individuals as a function of age. In line with the life-cycle hypothesis of risk aversion, we assume that low-wealth individuals start their independent financial life at age 20 and have a constant rate of savings $s$ between ages 20 and 60, then retire at 60 and completely dissave all accumulated wealth till the age of 80 . The savings of the low-wealth individuals are derived from their wage income. If the cohort-specific endowment with human capital is assumed as given, at any time $t$ each individual cohort member receives the same wage $w(t)$. This wage may, however, increase over time due to capital accumulation.

The wealth of each low-wealth individual at time $t$ and age $a$ is equal to $V_{j}(a, t)$. Index $j$ denotes the type; we will distinguish between $j=l, 1$ (lowwealth, active, ages 20-60) and $j=l, 2$ (low-wealth, retired, ages 60-80).

For simplicity, we assume that the consumption path of low-wealth individuals is growing over time and includes the share $1-s$ of their wage income and all capital income. In consistency with the fourth stylized fact, we do not include the dividends on stock and the interest on bond holdings, respectively, in the wealth accumulation equation but assume that they are consumed rather than saved. This implies increasing sales of securities over lifetime.

\footnotetext{
${ }^{17}$ If the age specific wealth schedule would be increasing in age, our specific inheritance procedure would otherwise result in a discontinuous wealth distribution among high-wealth individuals.
} 
Then, wealth for a low-wealth individual at time $t$ and of age $20<a<60$ is given by:

$$
V_{l, 1}(a, t)=s \int_{t-a+20}^{t} w(u) d u=\frac{s w(0)}{r_{S}} e^{r_{S} t}\left(1-e^{(-a+20) r_{S}}\right) .
$$

The maximal wealth is accumulated by the age of 60 and given by:

$$
V_{l, 1}(60, t)=\frac{s w(0)}{r_{S}} e^{r_{S} t}\left(1-e^{-40 r_{S}}\right) .
$$

For low-wealth individuals in pension age, linear dissaving is assumed, so that they have zero wealth at the end of their life. Since the individuals having age $a>60$ at time $t$ started dissaving at time $t-a+60$, we need to start from the wealth for their cohort accumulated from (labor) income at that moment. Thus,

$$
\begin{array}{r}
V_{l, 2}(a, t)=V_{l, 1}(60, t-a+60)[1-0.05(a-60)]= \\
\frac{s w(0)}{r_{S}} e^{r_{S} t}\left(1-e^{-40 r_{S}}\right) e^{r_{S}(60-a)}[1-0.05(a-60)] .
\end{array}
$$

In Appendix 2 we show that our individual paths of wealth accumulation are consistent with the aggregate behavior of our economy which is assumed to grow at a constant rate $r_{S}$.

\section{Aggregate Demand for Assets and Market Equi- librium}

\subsection{Demand for Stocks}

We assume that high-wealth individuals accumulate their wealth in stocks only ${ }^{18}$ and never dissave it, using only labor income for consumption and working until age of 80. Demand for stocks by high-wealth individuals at time $t$ is:

$$
D_{r}^{S}(t)=\int_{20}^{80} \sigma B(t-a) V_{r}(a, t) d a .
$$

Since the saving behavior for low-wealth individuals depends on whether they are in the labor force or in pension age, we need to separately define the demand

\footnotetext{
${ }^{18}$ Recalling equation (1), $V(a, t)$ is so large that $P(a, t)$ converges towards 1 .
} 
for stocks for each of these groups. Demands for stocks by active low-wealth individuals (age 20-60, index $l, 1$ ) and retired low-wealth individuals (60-80, index $l, 2)$ at time $t$ is given by the formulae:

$$
\begin{aligned}
& D_{l, 1}^{S}(t)=\int_{20}^{60}(1-\sigma) B(t-a) V_{l, 1}(a, t) P(a) d a, \\
& D_{l, 2}^{S}(t)=\int_{60}^{80}(1-\sigma) B(t-a) V_{l, 2}(a, t) P(a) d a,
\end{aligned}
$$

where the propensity to invest in stock $P(a)$ is assumed to depend only on current age $a$ and not on wealth and henceforth not on time $t$

$$
P(a)=\frac{40}{40+a} .
$$

The reason for such a specification is to avoid the problem of different risk aversion at the same age for different generations, which leads to both conceptuallyeconomic and mathematical difficulties. According to our definition of $P(a)$, a low-wealth individual holds $2 / 3$ of wealth in stocks at age 20 and drives down this fraction till the age of 80 to $1 / 3$ in the limit. Recall, however, that due to dissaving, wealth will be zero at age 80 such that there will be no bequests from low-wealth individuals.

Market equilibrium for stocks. We have to aggregate the demand for stocks with the supply, assuming an initial public offer of $\bar{S}$ stocks at time $t=0$ (we set the initial time arbitrary), which is growing exponentially by a mechanism of dividend nominated in new stocks:

$$
D_{r}^{S}(t)+D_{l, 1}^{S}(t)+D_{l, 2}^{S}(t)=\bar{S} e^{r_{S} t} p_{S}(t)
$$

Here $p_{s}(t)$ denotes the price dynamics of one share over time. ${ }^{19}$

\subsection{Demand for Bonds}

Bonds are demanded only by low-wealth individuals in working age, $(l, 1)$ and retirement age $(l, 2)$ :

$$
\begin{aligned}
& D_{l, 1}^{F}(t)=\int_{20}^{60}(1-\sigma) B(t-a) V_{l, 1}(a, t)(1-P(a)) d a \\
& D_{l, 2}^{F}(t)=\int_{60}^{80}(1-\sigma) B(t-a) V_{l, 2}(a, t)(1-P(a)) d a .
\end{aligned}
$$

\footnotetext{
${ }^{19}$ Note that equation (9) represents a stock and not a flow equilibrium.
} 
Both groups have positive demand for bonds at each time $t$. Hence, the total supply of bonds is also positive. In other words, we do not have a story about bonds used for wealth transfer across generations with zero net supply, but rather a story about bond market used to hold state debt. We assume that corporate debt is not existing, and bonds do not have any effect on the growth rate of the economy. The return on bonds, $r_{F}$, may be positive, but always below the return on stocks: $0 \leq r_{F}<r_{S}$.

Market equilibrium for bonds. Assuming an initial stock of bonds equal to $\bar{F}$ at time $t=0$ and a growth rate of bonds equal to $r_{S}$ we arrive at the market clearing condition for bonds:

$$
D_{l, 1}^{F}(t)+D_{l, 2}^{F}(t)=\bar{F} e^{r_{S} t} p_{F}(t)
$$

where $p_{F}$ denotes the price dynamics of one bond over time.

\section{Constant Cohort Size: A Benchmark Model}

We start from a benchmark model that incorporates our basic elements of financial markets outlined in the previous sections and assume that all cohorts are of equal size which we set equal to $B(t-a) \equiv 1$. This corresponds to the notion of a demographically stationary economy which we define as follows:

Definition 1 A demographically stationary economy is an economy with a constant rate of balanced growth (due to the accumulation of physical and human capital) and a stationary population.

Consider the equilibrium conditions for the stock and bond market. Upon substituting (5), (6) and (7) into (9) and respectively (10) and (11) into (12) and recalling (2), (3) and (4) we obtain:

$$
\begin{array}{r}
\sigma \int_{20}^{80} V_{r}(0,0) e^{r_{S} t} B(t-a) d a+ \\
(1-\sigma) \frac{s w(0)}{r_{S}} e^{r_{S} t}\left[I_{1}(B)+\left(1-e^{-40 r_{S}}\right) I_{2}(B)\right]=\bar{S} e^{r_{S} t} p_{S}(t), \\
(1-\sigma) \frac{s w(0)}{r_{S}} e^{r_{S} t}\left[I_{3}(B)+\left(1-e^{-40 r_{S}}\right) I_{4}(B)\right]=\bar{F} e^{r_{S} t} p_{F}(t),
\end{array}
$$


where $I_{i}(B), i=1, \ldots 4$ are functionals of $B(t-a)$ :

$$
\begin{aligned}
I_{1}(B) & \equiv \int_{20}^{60}\left(1-e^{-r_{S}(a-20)}\right) \frac{40}{40+a} B(t-a) d a \\
I_{2}(B) & \equiv \int_{60}^{80} e^{r_{S}(60-a)}\left[1-\frac{a-60}{20}\right] \frac{40}{40+a} B(t-a) d a \\
I_{3}(B) & \equiv \int_{20}^{60}\left(1-e^{-r_{S}(a-20)}\right) \frac{a}{40+a} B(t-a) d a \\
I_{4}(B) & \equiv \int_{60}^{80} e^{r_{S}(60-a)}\left[1-\frac{a-60}{20}\right] \frac{a}{40+a} B(t-a) d a .
\end{aligned}
$$

Upon substituting $B(t-a) \equiv 1$ and by canceling $e^{r_{S} t}$ on both sides of equation (13) and (14), we obtain the result of constant stock and bond prices over time. This is a desired property of the benchmark model, since possible price changes must then be attributable to cohort size heterogeneity.

Proposition 1 For the benchmark case of a demographically stationary economy, the price of stocks and bonds is constant over time, given that the total number of stocks and bonds at the market grows exponentially with the rate of return at the stock market.

\section{A Model with Varying Cohort Size}

\subsection{Modelling the baby-boom}

By comparison with the benchmark model, the outcome of the model with heterogeneous cohort size developed subsequently permits to identify the demographic effect of a baby-boom on the dynamics of asset prices.

We will study such an effect drawing upon the simplest kind of heterogeneity, viz. the number of births equal to one in all cohorts, except for that of the babyboom, which has size $1+\epsilon$, where $\epsilon>0$ may be sufficiently large (of order 1). This perturbation does not affect the overall population size much, which also stays constant at the level $80+\epsilon$ during the whole life of the baby-boom cohort. Such a perturbation can be modelled by a $\delta$-function. Let the baby-boom generation be born at time $t=0$. Then between $t=0$ and $t=80$ the population will be constant, of size $80+\epsilon$, with the baby-boom generation moving by one time step each year as it ages by one year. We will use the following mathematical property of the $\delta$-function in further calculations. 
Property of the $\delta$-function. For any continuous function $G(a)$, defined on the interval $\left[a_{1}, a_{2}\right]$, we have:

$$
\begin{aligned}
\int_{a_{1}}^{a_{2}} \delta(t-a) G(a) d a & =G(t), & & \forall t \in\left[a_{1}, a_{2}\right] ; \\
\int_{a_{1}}^{a_{2}} \delta(t-a) G(a) d a & =0, & & \forall t \notin\left[a_{1}, a_{2}\right] .
\end{aligned}
$$

More detailed information about the $\delta$-function is provided in Appendix 3 .

\subsection{Demand for stocks and bonds}

Demand for stocks and bonds at time $20 \leq t \leq 80$ will increase as a consequence of the baby boom generation that 'steps' through time as it ages. For $t<20$ and $t>80$ the results of our benchmark model apply. In each time period $t \in$ $[20,80]$ there will be $\epsilon \sigma$ additional high-wealth and $(1-\sigma) \epsilon$ additional low-wealth individuals.

Consider the total birth density function, formally given by:

$$
B(t-a)=1+\epsilon \delta(t-a) \quad 0 \leq t \leq 80 .
$$

It formally corresponds to a cohort of size $1+\epsilon$ that is born at $t=0$. As the baby boom cohort 'steps' through its life the demand for stocks and bonds will change in period $t \in[20,80]$.

According to the property of the $\delta$-function, if $t \in\left[a_{1}, a_{2}\right]$, we have:

$$
\begin{aligned}
\int_{a_{1}}^{a_{2}} B(t-a) G(a) d a= & \int_{a_{1}}^{a_{2}} G(a) d a+\epsilon \int_{a_{1}}^{a_{2}} \delta(t-a) G(a) d a= \\
& \int_{a_{1}}^{a_{2}} G(a) d a+\epsilon G(t) .
\end{aligned}
$$

Upon substitution of (15) and applying (16) to the derivation of the stock and bond market equilibrium in the previous section (equation (13) and (14)) we can derive the demand for stocks and bonds as a consequence of the baby boom.

For $t \in[0,20]$, nothing will happen on the stock and bond market, in comparison with our benchmark model. (Neither high-wealth, nor low-wealth babyboomers are creating additional demand in this period.)

Demand for stocks. For $t \in[20,80]$ the total demand of stocks by high-wealth individuals is given by:

$$
D_{r}^{S}(t)=\sigma e^{r_{S} t} V_{r}(0,0) \int_{20}^{80} B(t-a) d a=\sigma e^{r_{S} t} V_{r}(0,0)(60+\epsilon) .
$$


The total wealth of low-wealth individuals (active and retired), invested in stocks at time $t \in[20,60]$ equals:

$$
\begin{aligned}
& D_{l, 1}^{S}(t)=(1-\sigma) \frac{s w(0)}{r_{S}} e^{r_{S} t}\left[I_{1}(1)+\epsilon\left(1-e^{-r_{S}(t-20)}\right) \frac{40}{40+t}\right] \\
& D_{l, 2}^{S}(t)=(1-\sigma) \frac{s w(0)}{r_{S}} e^{r_{S} t}\left(1-e^{-40 r_{S}}\right) I_{2}(1)
\end{aligned}
$$

For $t \in[60,80]$ the demand for stocks by low-wealth individuals is given by:

$$
\begin{aligned}
& D_{l, 1}^{S}(t)=(1-\sigma) \frac{s w(0)}{r_{S}} e^{r_{S} t} I_{1}(1) \\
& D_{l, 2}^{S}(t)=(1-\sigma) \frac{s w(0)}{r_{S}} e^{r_{S} t}\left(1-e^{-40 r_{S}}\right)\left[I_{2}(1)+\epsilon e^{r_{S}(60-t)}\left[1-\frac{t-60}{20}\right]\left[\frac{40}{40+t}\right]\right] .
\end{aligned}
$$

Demand for bonds. There is no demand for bonds by high-wealth individuals. For time $t \in[20,60]$, the demand for bonds is given by:

$$
\begin{aligned}
& D_{l, 1}^{F}(t)=(1-\sigma) \frac{s w(0)}{r_{S}} e^{r_{S} t}\left[I_{3}(1)+\epsilon\left(1-e^{-r_{S}(t-20)}\right) \frac{t}{40+t}\right] \\
& D_{l, 2}^{F}(t)=(1-\sigma) \frac{s w(0)}{r_{S}} e^{r_{S} t}\left(1-e^{-40 r_{S}}\right) I_{4}(1)
\end{aligned}
$$

For time $t \in[60,80]$, the baby-boom cohort retires and the demand for bond changes:

$$
\begin{aligned}
D_{l, 1}^{F} & =(1-\sigma) \frac{s w(0)}{r_{S}} e^{r_{S} t} I_{3}(1) \\
D_{l, 2}^{F} & =(1-\sigma) \frac{s w(0)}{r_{S}} e^{r_{S} t}\left(1-e^{-40 r_{S}}\right)\left[I_{4}(1)+\epsilon e^{r_{S}(60-t)}\left[1-\frac{t-60}{20}\right]\left[\frac{t}{40+t}\right]\right]
\end{aligned}
$$

\subsection{Market equilibrium for stocks and bonds at time$$
20<t<60 \text {. }
$$

Taking into account that the baby-boom represents a small perturbation for the overall economy (less than $1 \%$ of population added), we can still use the exponential formulae for economic growth. However, the baby boom cohort will have an effect on the dynamics of market prices $p_{S}(t)$ and $p_{F}(t)$ for $20 \leq t \leq 80$. 
Stock market. Upon substitution of (17), (18) and (19) into (9) we obtain the market clearing condition for stocks at $20<t<60$ :

$$
\begin{array}{r}
(1-\sigma) \frac{s w(0)}{r_{S}} e^{r_{S} t}\left[I_{1}(1)+\epsilon\left(1-e^{-r_{S}(t-20)}\right) \frac{40}{40+t}\right] \\
+(1-\sigma) \frac{s w(0)}{r_{S}} e^{r_{S} t}\left(1-e^{-40 r_{S}}\right) I_{2}(1)+\sigma e^{r_{S} t} V_{r}(0,0)(60+\epsilon)=\bar{S} e^{r_{S} t} p_{S}(t) .
\end{array}
$$

It is immediately clear that a constant price for stocks is no longer sustained. The reason is the additional term in the square bracket that is proportional to the size of the additional babies $\epsilon$ from the baby boom cohort.

Dividing both sides of equation (26) by $\bar{S} e^{r_{S} t}$ yields the price dynamics of stocks for $20<t<60$ :

$$
p_{S}(t)=C_{1}+\epsilon C_{2} h_{1}(t)
$$

where

$$
\begin{aligned}
C_{1} & \equiv(1-\sigma) \frac{s w(0)}{r_{S} \bar{S}}\left[I_{1}(1)+\left(1-e^{-40 r_{S}}\right) I_{2}(1)\right]+\sigma \frac{V_{r}(0,0)}{\bar{S}}(60+\epsilon), \\
C_{2} & \equiv \frac{(1-\sigma) s w(0)}{r_{S} \bar{S}}, \\
h_{1}(t) & \equiv\left(1-e^{-r_{S}(t-20)}\right) \frac{40}{40+t} .
\end{aligned}
$$

Lemma 1 There exists a time interval $[20, \tau]$ where the price of stocks increases as the result of the baby-boom cohort entering the labor market.

\section{PROOF:}

Since $p_{S}^{\prime}(t)=\epsilon C_{2} h_{1}^{\prime}(t)$, the sign of the change in stock prices depends on $h_{1}^{\prime}(t)$. From $h_{1}(20)=0$ and $h_{1}(t)>0$ for $20<t<60$ together with the fact that $h_{1}(t)$ is continuously differentiable, it follows that $h_{1}(t)$ is an increasing function in some neighborhood $[20,20+\delta]$.

Note, that the value of $r_{S}$ will determine whether the maximum of $h_{1}(t)$ is obtained within the interval $20<t<60$. Let us denote the first multiplier in $h_{1}$ as $G(t) \equiv 1-e^{-r_{S}(t-20)}$ (accumulation factor). Then $h_{1}=G(t) P(t)$ where $P(t)$ denotes the portfolio rebalancing factor (see formula (8)). For $t>20, G(t)$ is growing from 0 to 1 , while $P(t)$ always declines. For low values of $r_{S}$, growth of the first is still significant for relatively high values of $t$, while for high values of $r_{S}$ the exponent in $G(t)$ is almost zero at median values of $t$, and $G(t)$ approaches 
1 asymptotically. In this case, the effect of a declining share of stocks in the portfolio dominates, and we get an overall decline in $h_{1}$, hence in prices starting at some time $t<60$.

The economic intuition behind those results is as follows. Low-wealth individuals accumulate wealth at an over-exponential growth rate but the accumulation factor $G(t)$ is less pronounced for higher values of $r_{S}$. Hence, for higher values of $r_{S}$ the effect of the baby boom cohort on stock prices erodes faster, and we get the maximum of the stock prices already several years after the entry of the baby boom cohort into the labor market.

Lemma 1 underpins the results derived by Brooks (2000), Poterba (1998), Yoo (1994) and other authors that the recent stock market run-up in the United States was - at least in part - due to the baby-boom cohort entering the peak savings period. However, we show that though the price of stocks increases after the baby-boom cohort starts to work, a high enough value of $r_{S}$ may induce prices of stock to decline already several years after the baby boom cohort entered the labor force. In section 8 where we present simulations and calibrations of our model we shall show that while the less wealthy baby-boomers contribute to a continuous increase of stock prices during their economic active life, more wealthy babyboomers may be responsible for a rapid increase of stock prices when they start economic activity.

Bond market. Upon substitution of (22) and (23) into (12) we obtain the market clearing condition for bonds for time periods $20<t<60$ :

$$
\begin{gathered}
(1-\sigma) \frac{s w(0)}{r_{S}} e^{r_{S} t}\left[I_{3}(1)+\epsilon\left(1-e^{-r_{S}(t-20)}\right) \frac{t}{40+t}\right]+ \\
(1-\sigma) \frac{s w(0)}{r_{S}} e^{r_{S} t}\left(1-e^{-40 r_{S}}\right) I_{4}(1)=\bar{F} / e^{r_{S} t} p_{F}(t) .
\end{gathered}
$$

Dividing both sides of equation (28) by $\bar{F} e^{r_{S} t}$ yields the price dynamics of bonds for $20<t<60$ :

$$
p_{F}(t)=D_{1}+\epsilon D_{2} h_{3}(t)
$$

where

$$
\begin{aligned}
D_{1} & \equiv(1-\sigma) \frac{s w(0)}{r_{S} \bar{F}}\left[I_{3}(1)+\left(1-e^{-40 r_{S}}\right) I_{4}(1)\right], \\
D_{2} & \equiv(1-\sigma) \frac{s w(0)}{r_{S} \bar{F}} \\
h_{3}(t) & \equiv\left(1-e^{-r_{S}(t-20)}\right) \frac{t}{40+t} .
\end{aligned}
$$


Lemma 2 When the baby-boom cohort enters the labor force, demand for bonds is rising, pushing their price up.

\section{PROOF:}

Since $p_{F}^{\prime}(t)=\epsilon D_{2} h_{3}^{\prime}(t)$ and $h_{3}^{\prime}(t)$ is strictly positive for $t>20$, the price of bonds will rise.

We may explain the results of Lemma 1 and Lemma 2 as follows: As lowwealth individuals age they invest an increasing share of their wealth in bonds. In addition, wealth increases with age, such that demand for bonds will unambiguously rise over the considered time period during which baby boomers are active in the labour market. In case of stock prices we may observe an initial increase followed by a decline in stock prices as the baby boom generation ages. Such a reversal in the price change may take place if the wealth invested in stocks by high-wealth individuals will not rise sufficiently with age in order to compensate the falling demand for stocks by low-wealth individuals when they age.

\subsection{Market equilibrium for stocks and bonds at time}

$$
60<t<80
$$

Stock market Upon substitution of (17), (20) and (21) into (9) we obtain the market clearing condition for stocks at $60<t<80$ :

$$
\begin{array}{r}
\sigma e^{r_{S} t} V_{r}(0,0)(60+\epsilon)+(1-\sigma) \frac{s w(0)}{r_{S}} e^{r_{S} t} I_{1}(1)+ \\
+(1-\sigma) \frac{s w(0)}{r_{S}} e^{r_{S} t}\left(1-e^{-40 r_{S}}\right)\left[I_{2}(1)+\epsilon e^{r_{S}(60-t)}\left[1-\frac{t-60}{20}\right]\left[\frac{40}{40+t}\right]\right]= \\
\bar{S} e^{r_{S} t} p_{S}(t) .
\end{array}
$$

Dividing both sides of equation (30) by $\bar{S} e^{r_{S} t}$ yields the price dynamics of stocks for $60<t<80$ :

$$
p_{S}(t)=C_{1}+\epsilon C_{3} h_{2}(t)
$$

with

$$
\begin{aligned}
C_{3} & \equiv 2 \frac{(1-\sigma) s w(0)}{r_{S} \bar{S}}\left(1-e^{-40 r_{S}}\right) \\
h_{2}(t) & \equiv e^{r_{S}(60-t)} \frac{80-t}{40+t} .
\end{aligned}
$$

and $C_{1}$ as given in equation (27). 
Lemma 3 In the period $60<t<80$ when the baby-boom cohort retires, stock prices will decline.

PROOF:

Since $p_{S}^{\prime}(t)=\epsilon C_{3} h_{2}^{\prime}(t)$, and $h_{2}^{\prime}(t)<0$ it follows that $p_{S}^{\prime}(t)<0$ holds.

Bond market. Upon substitution of (24) and (25) into (12) we obtain the market clearing condition for bonds for time periods $60<t<80$ :

$$
\begin{array}{r}
(1-\sigma) \frac{s w(0)}{r_{S}} e^{r_{S} t} I_{3}(1)+(1-\sigma) \frac{s w(0)}{r_{S}} e^{r_{S} t}\left(1-e^{-40 r_{S}}\right)\left\{I_{4}(1)+\right. \\
\left.\epsilon e^{r_{S}(60-t)}\left[1-\frac{t-60}{20}\right] \frac{t}{40+t}\right\}=\bar{F} e^{r_{S} t} p_{F}(t)
\end{array}
$$

Dividing both sides of equation (32) by $\bar{F} e^{r_{S} t}$ yields the price dynamics of bonds for $60<t<80$ :

$$
p_{F}(t)=D_{1}+\epsilon D_{3} h_{4}(t)
$$

with

$$
\begin{aligned}
D_{3} & \equiv(1-\sigma) \frac{s w(0)}{r_{S} \bar{F}}\left(1-e^{-40 r_{S}}\right) \\
h_{4} & \equiv e^{r_{S}(60-t)} \frac{80-t}{20} \frac{t}{40+t}
\end{aligned}
$$

and $D_{1}$ as given in equation (29).

Lemma 4 In the period $60<t<80$ when the baby-boom cohort retires, bond prices will decline.

PROOF:

Since $p_{F}^{\prime}(t)=\epsilon D_{3} h_{4}^{\prime}(t)$ and

$$
\begin{array}{r}
\frac{d}{d t}\left(\frac{(80-t) t}{20(40+t)}\right)=\frac{(t-60-20 \sqrt{20})(t-60+20 \sqrt{20})}{20(40+t)^{2}}<0 \\
\frac{d}{d t}\left(e^{r_{S}(60-t)}\right)=-r_{S} e^{r_{S}(60-t)}>0
\end{array}
$$

the price of bonds will decline. 
The results in Lemma 4 reflect the interplay between dissavings and growing demand for bonds by low-wealth individuals that results from growing risk aversion with age. For any value of interest, the effects of dissavings is always stronger than the changing portfolio effect. Hence, bond prices will decline. Similarly, in case of stock prices, there will be an unambiguous decline in the price implying that for $60<t<80$ the decrease in the demand for stocks by low-wealth individuals will overcompensate the increase in wealth and hence stock demand by high-wealth individuals.

This model thus generates results that are observationally equivalent to the standard outcome of earlier work:

Proposition 2 If wealth is distributed uniformly across ages of high-wealth individuals, there is no counterbalance to the higher demand for stocks when the baby-boom cohort enters the labor force. This leads to an increase of stock prices caused by a purely demographic effect. The retirement of the baby-boom cohort similarly causes stock prices to fall. The magnitude of the effect is proportional to the fraction of the additional population in the baby-boom cohort in relation to the total population.

However, in extension of previous results, there may be a strictly internal maximum of stock prices (with respect to the labor market participation of the babyboom cohort) such that the decline of stock prices sets in well before collective retirement.

\section{Wealth Heterogeneity Across Ages of High-Wealth Individuals}

Assume that initial wealth across high-wealth individuals is distributed non-uniformly. Then their demand for stocks is given by the formula

$$
D_{r}^{S}(t)=\sigma e^{r_{S} t} V_{r}(0,0)\left[\int_{20}^{80} \rho(a) d a+\epsilon \rho(t)\right] .
$$

We denote the integral of the wealth distribution across ages by $\int \rho(a) d a \equiv W_{R}$ (before it was equal to 60).

By assumption, high-wealth individuals do not demand bonds such that the bond market will not be affected by the change in the income distribution of highwealth individuals. Consequently the results for bond markets from the previous section hold and we shall therefore concentrate on stock markets only. 
To determine the equilibrium at the stock market we proceed as in the previous section, adding the term for baby-boomers of high wealth, which now depends on $t$ as well. For $20<t<60$, we have the following price dynamics:

$$
p_{S}(t)=C_{4}+\epsilon\left[C_{2} h_{1}(t)+\sigma \frac{V_{r}(0,0)}{\bar{S}} \rho(t)\right]
$$

where

$$
C_{4} \equiv(1-\sigma) \frac{s w(0)}{r_{S} \bar{S}}\left[I_{1}(1)+\left(1-e^{-40 r_{S}}\right) I_{2}(1)\right]+\sigma \frac{V_{r}(0,0)}{\bar{S}} W_{R}
$$

and $C_{2}$ is given as in equation (27).

Lemma 5 Even under the assumption of a heterogeneous wealth distribution across cohorts of high-wealth individuals, stock prices will increase when the baby-boom cohort starts to work.

\section{PROOF:}

We need to show that $p_{S}^{\prime}(t)>0$ near $t=20$. This immediately follows from the assumption $\rho^{\prime}(a)>0, \forall a$. We have $\rho^{\prime}(20)>0$ and $h_{1}^{\prime}(20)>0$. This leads to $p_{S}^{\prime}(20)>0$.

For $60<t<80$, the equilibrium at the stock market leads to the following price dynamics:

$$
p_{S}(t)=C_{4}+\epsilon\left[C_{3} h_{2}(t)+\sigma \frac{V_{r}(0,0)}{\bar{S}} \rho(t)\right]
$$

where $C_{3}$ is given as in equation (31) and $C_{4}$ as in equation (35).

Lemma 6 Under the assumption of a heterogenous wealth distribution across cohorts of high-wealth individuals, stock prices may either rise, stay constant or decrease when the baby boom generation retires at $60<t<80$.

PROOF:

We have: $\rho^{\prime}(t)>0$, but $\frac{d}{d t} h_{2}(t)<0$. Since one of the derivatives depends parametrically on $r_{S}$ and therefore can take on any negative value in the neighbourhood of zero, while $\rho^{\prime}(t)$ can take on values in the positive neighbourhood of zero only, $p_{S}^{\prime}(t)$ has an ambiguous sign for $t \in[60,80]$.

Proposition 3 If we allow for an increase of wealth of high-wealth individuals not only across time, but also across cohorts at the same time, then the retirement 
of the baby-boom cohort might not produce a decline of the stock market index. The reduced demand of low-wealth individuals for stocks after retirement can be compensated for by an increased demand by high-wealth individuals. If highwealth baby-boomers receive a sufficiently large flow of bequests close to the age of 60 (i.e. $\rho^{\prime}(60)$ is high), their growing demand for stocks can overcompensate the dissaving of low-wealth retirees and a decline of stock prices can be avoided. However, if $\sigma$ and $\rho^{\prime}(60)$ are low, a decline of stock prices may take place.

\section{Calibration and Simulation}

Since our results depend on various parameters, it is important to (a) select realistic values for the parameters and (b) investigate the sensitivity of our results with respect to those parameters that affect the outcome qualitatively. Following these considerations we assumed that $\epsilon=1$ throughout all simulations. This gives a substantial increase of the size of the baby-boom cohort (by 100\%) in comparison to the benchmark model, and at the same time implies a small change for the total population, just an increase of $1.25 \%$ which in turn will imply an average price rise of $1.25 \%$ for all assets. However, as already indicated we are mainly interested how the price dynamics will change qualitatively if we change specific parameter values. For some of our results the choice of $r_{S}$ is important; we choose $r_{S}=0.04$, keeping in mind that it corresponds to the growth rate in the economy. We start our simulations from the case of a homogeneous wealth distribution across ages of high-wealth individuals (section 6), and then will move to the case of a heterogeneous wealth distribution (section 7).

First, we need to calculate the value of the integrals $I_{i}$, which depend on $r_{S}$ only. Setting $r_{S}=0.04$ and assuming equal birth cohorts of size one, yields the following values for the integrals:

$$
\begin{aligned}
I_{1}(1) & =9.559, I_{2}(1)=2.950, I_{3}(1)=10.488, I_{4}(1)=4.842, \\
J_{1} & \equiv I_{1}(1)+\left(1-e^{-40 r_{S}}\right) I_{2}(1)=11.914 \\
J_{2} & \equiv I_{3}(1)+\left(1-e^{-40 r_{S}}\right) I_{4}(1)=14.352 .
\end{aligned}
$$

We set the initial price for stocks and bonds equal to one and assume that a baby boom occurs at $t=0$. For $0<t<20$ the price dynamics for stocks and bonds will be constant as in the baseline model of section 5 . When the baby boom enters the labour market at $t=20$, price dynamics of bonds and stocks will change according to equations (27) and (29) for $t \in[20,60]$ and according to equations (31) and (33) for $t \in[60,80]$. Without loss of generality, we choose $\bar{S}=1$. Let us introduce a new variable, $\gamma$, which represents the share of wealth 
Table 2: Parameter values for $r_{S}=0.04$.

\begin{tabular}{|c|c|c|c|c|c|c|c|}
\hline$\gamma$ & $C_{1}$ & $D_{1}$ & $C_{2}$ & $C_{3}$ & $\bar{F}$ & $D_{2}$ & $D_{3}$ \\
\hline 0.3 & 1.005 & 1 & 0.0587 & 0.0938 & 0.8433 & 0.0697 & 0.0556 \\
\hline 0.5 & 1.0083 & 1 & 0.0419 & 0.0669 & 0.6023 & 0.0697 & 0.0556 \\
\hline 0.7 & 1.0116 & 1 & 0.0252 & 0.0401 & 0.3614 & 0.0697 & 0.0556 \\
\hline 0.8 & 1.0133 & 1 & 0.0168 & 0.0268 & 0.241 & 0.0697 & 0.0556 \\
\hline
\end{tabular}

held by high-wealth individuals in the total value of stocks:

$$
\gamma \equiv \frac{\sigma}{\bar{S}} V_{r}(0,0) 60 .
$$

To keep the 'non-perturbed' prices equal at the level of one we set $C_{1}-\epsilon \frac{\gamma}{60}=$ $1, D_{1}=1$. From these conditions we can next derive the value of $C_{2}$ and the initial stock of bonds $\bar{F}$.

$$
\begin{aligned}
C_{1}-\epsilon \frac{\gamma}{60} & =C_{2} J_{1}+\gamma=1 \Rightarrow C_{2}=\frac{1-\gamma}{J_{1}}, \\
D_{1} & =\frac{C_{2}}{\bar{F}} J_{2}=\frac{1-\gamma}{\bar{F}} \frac{J_{2}}{J_{1}}=1 \Rightarrow \bar{F}=(1-\gamma) \frac{J_{2}}{J_{1}} .
\end{aligned}
$$

For the remaining coefficients $D_{2}, C_{3}$ and $D_{3}$ we can derive the following expressions:

$$
\begin{aligned}
D_{2} & =C_{2} / \bar{F}=1 / J_{2}, \\
C_{3} & =2 C_{2}\left(1-e^{-40 r_{S}}\right), \\
D_{3} & =\frac{C_{2}}{\bar{F}}\left(1-e^{-40 r_{S}}\right) .
\end{aligned}
$$

For any value of $\gamma$ we can then determine the value of $C_{i}, D_{i}, i=1,2,3$ and the initial stock of bonds $\bar{F}$. The results are given in the Table 2 (the case $\left.r_{S}=0.04\right)$.

In order to illustrate the sensitivity of our results on the interest rate $r_{S}$, similar coefficients were calculated for $r_{S}=0.08$ (Table 3).

\subsection{Wealth homogeneity across ages of high-wealth individuals}

Insert Figure 2.a here. 
Table 3: Parameter values for $r_{S}=0.08$.

\begin{tabular}{|c|c|c|c|c|c|c|c|}
\hline$\gamma$ & $C_{1}$ & $D_{1}$ & $C_{2}$ & $C_{3}$ & $\bar{F}$ & $D_{2}$ & $D_{3}$ \\
\hline 0.3 & 1.005 & 1 & 0.0441 & 0.0847 & 0.803 & 0.0550 & 0.0527 \\
\hline 0.5 & 1.0083 & 1 & 0.0315 & 0.0605 & 0.5735 & 0.0550 & 0.0527 \\
\hline 0.7 & 1.0116 & 1 & 0.0189 & 0.0363 & 0.344 & 0.0550 & 0.0527 \\
\hline 0.8 & 1.0133 & 1 & 0.0126 & 0.0242 & 0.229 & 0.0550 & 0.0527 \\
\hline
\end{tabular}

In the first set of simulations we choose $\epsilon=1$ and $r_{S}=0.04$. Figure 2.a shows the evolution of stock and bond prices for $20<t<80$ for values of $\gamma$ equal to $0.3,0.5,0.7$ and 0.8. Note, that bond prices do not depend on $\gamma$. For all price developments we observe a monotonically increasing function for $20<t<60$. The fact that stock prices start from a level that is above 1 at $t=20$ is caused by our assumption that people aged 20 already start off with a positive wealth if we assume age-homogeneity of high-wealth individuals. ${ }^{20}$ While the initial shock is of order $1-2 \%$, the overall appreciation of the stock is of magnitude $2-2.5 \%$.

The value of the shift in stock prices at time $t=20$ is proportional to both $\epsilon$ and $\gamma$. Thus, the stock price appreciation at $t=20$ is proportional to the relative size of the baby boom cohort $(\epsilon)$ and also to the share of more wealthy individuals $(\gamma)$ who got their bequest at age $20 .{ }^{21}$ The process of wealth accumulation by less wealthy baby-boomers is responsible for the continuous change of stock prices after their entry into the labor market $(t>20)$. The slope of $p_{S}(t)$ is more pronounced in a society with a higher fraction of wealth being hold by less wealthy individuals (lower $\gamma$ ).

For $60<t<80$ stock as well as bond prices decline monotonically. At $t=80$ all prices return to their stationary level that has been achieved before the baby boom cohort entered the financial market, which corresponds to an economy with a fully homogeneous age structure.

Insert Figure 2.b here.

In Figure 2.b we present the development of stock and bond prices for $r_{S}=$ 0.08. The main difference to the case of $r_{S}=0.04$ is that the stock price reaches its maximal value at $t=46$ (though the decline between $t=46$ and $t=60$ is

\footnotetext{
${ }^{20}$ In reality this discontinuity can be smoothed out, since not all agents become economically active at the same age.

${ }^{21}$ In reality, the process of receiving bequest as well as starting economic activity is smooth. That is why the sharp appreciation of stocks is normally not a consequence of the baby boom effect. In the next subsection we will see that all prices evolve continuously, if the flow of inheritances is continuous across ages.
} 
almost invisible, and looks more like a plateau). Another interesting fact is that their exist two time/age points where stock prices (independent of $\gamma$ ) intersect (this holds for Figure 2.a as well as Figure 2.b). This can be understood from the following mathematical example. Consider a family of functions, $f_{\gamma}(t)=$ $\gamma 1+(1-\gamma) t$. All these functions intersect at $t=1 .^{22}$ The economic intuition behind the existence of the intersection of stock prices is the following. The share of wealth of more wealthy agents, $\gamma$, determines the upward shift at $t=20$, while the share of less wealthy agents, $1-\gamma$, determines the slope of the stock price over time. The higher the shift, the lower is the slope. Depending on the value of the slope, which is also a function of $r_{S}$, at some time $t\left(r_{S}\right)$ both effects give the same cumulative price change. That is why we observe this intersection.

\subsection{Wealth heterogeneity across ages of high-wealth individu- als}

To make results comparable, we again set $\epsilon=1, r_{S}=0.04$, and use the calibration of the previous section as summarized in Table 2. We set $C_{4}$ equal to one to have the 'unperturbed' price equal to one. Furthermore we assume that wealth of high-wealth individuals grows linearly with age, according to the formula $\rho(a)=$ $(a-20) / 30, a \in[20,80]$. The functional form of $\rho(a)$ implies that high-wealth individuals start from zero wealth at age 20, but wealth grows to the level 2 at age 80. Henceforth, the average wealth across cohorts is 1 , which provides a good normalization. Also, we keep the definition of the factor $\gamma$, which is proportional to the ratio of the total wealth of high-wealth individuals in country's wealth. Since higher values of $\gamma$ lead to interesting price dynamics of the stocks we present results for $\gamma=0.9$ (in addition to simulations where we set $\gamma=0.3,0.5,0.7,0.8$. The corresponding values for $C_{2}$ and respectively $C_{3}$ if we set $\gamma=0.9$ are $C_{2}=$ 0.0168 and $C_{3}=0.0134$ respectively.

Since the bond market is not affected by the wealth distribution of high-wealth individuals we need to only study the price dynamics of stocks. For $20<t<60$, we have:

$$
p_{S}(t)=1+\epsilon\left[C_{2} h_{1}(t)+\frac{\gamma}{60} \frac{t-20}{30}\right] .
$$

It is easy to see that this formula differs from the homogeneous case of the wealth distribution only by the term that is proportional to $\gamma$. Note, that the numerator 60 stems from our definition of $\gamma$ :

$$
\sigma \frac{V_{r}(0,0)}{\bar{S}} \int_{20}^{80} \rho(a) d a=\gamma=\sigma \frac{V_{r}(0,0)}{\bar{S}} 60 .
$$

\footnotetext{
${ }^{22}$ We can write two equations for different values of $\gamma$ and get after equating them: $\left(\gamma_{1}-\gamma_{2}\right)=$ $\left(\gamma_{1}-\gamma_{2}\right) t$. The only solution is $t=1$, and the result does not depend on $\gamma$.
} 
Since the average value of $\rho$ is one, $\sigma V_{r} / \bar{S}=\gamma / 60$.

Similarly, for $60<t<80$, we have the formula:

$$
p_{S}(t)=1+\epsilon\left[C_{3} h_{2}(t)+\frac{\gamma}{60} \frac{t-20}{30}\right] .
$$

Insert Figure 3 here.

Interestingly, for low values of $\gamma(0.3$ and 0.5$)$ stock prices decline when babyboomers retire (Figure 3). By contrast, for high values of $\gamma=0.9$ stock prices increase, thus constituting an effect opposite to received wisdom! For the intermediate case, $\gamma=0.8$ or $\gamma=0.7$, the resulting pattern of stock prices is U-shaped.

\section{Conclusions}

While - following Raymond Queneau in "A Model History" - 'religions tend to disappear with man's good fortune', a real fortune, once acquired, is likely to have a life of its own, with life expectancy generally extending beyond that of its acquirer. May this be because of altruistic motives or because of the sheer difficulty to consume a large fortune within a man's short period of life, in its quality of a legacy a fortune may probably contribute to render homage but definitely not an egalitarian wealth distribution.

Starting from the purely positive point of view that wealth is unequally distributed across the individual members of an economy, this paper pays tribute to the fact that the allocation of assets may not only be the result of age but also of wealth. Thus extending earlier work, in this paper we present and analytically solve a theoretical model that explicitly incorporates the concept of a wealth distribution to investigate the relationship between cohort size, population ageing, and capital market dynamics.

We first present a benchmark model with constant cohort size wherein the relative price of stocks and bonds turns out to be constant over time. Allowing for heterogeneous cohort size, more specifically, a baby boom, we thereafter replicate the standard result that stock prices increase when the baby boom cohort enters the labor force and decline during the ensuing retirement phase, provided that wealth is distributed uniformly across all cohorts of high-wealth individuals. The presented model, however, encompasses the possibility that the decline of stock prices sets in well before collective retirement of the baby boom cohort takes place.

Introducing wealth heterogeneity across cohorts of high-wealth individuals, we derive a well-defined but wide variety of resulting stock market regimes. While in line with previous work a baby boom incipiently triggers positive stock price 
dynamics by all means, its net impact on the capital market as the population ages unfolds is far from obvious. Depending on the steepness of the aggregate wealth distribution and the share of high-wealth individuals in total population, the supposedly negative stock market impact of population ageing may be offset or even be reversed. In the light of this result, it appears as if the usual assumption of an "average" or "representative" investor unduly camouflages the underlying asset market dynamics which is de facto characterized by mutually offsetting decisions of buying and selling stocks by individuals of distinct wealth.

Thus our results do not lend support to the received hypothesis that stock markets may be doomed to suffer from a meltdown as the baby-boom cohort retires. Instead, various factors, inter alia bequest heterogeneity and asset allocation preferences, contribute to attenuate the expected stock market decline. In parallel, appropriate policy targeting will have numerous levers at hand, relating to both demographic and economic variables such as fertility rates, life expectancy, debt issuing policy, and income taxation.

Paradoxically at first glance, an uneven wealth distribution may turn out beneficial in stabilizing stock markets, since the high-wealth individuals may provide for the much-needed additional demand for stocks that may at least partially if not completely (and, for that reason, even more than that) offset the detrimental price dynamics once the baby-boomers are going to dissave for consumption during retirement. From a normative point of view the received inter-generation contract may thus warrant supplementation by an inter-proprietor contract, deriving from the Kantian imperative that who has already benefitted most from the baby-boominduced rise of the stock market and who is most likely to continue to do so shall not miss out in times of need. 


\section{Appendices}

\subsection{Appendix 1: Macroeconomic Framework}

The economy where both capital and wages grow exponentially, is a standard model from neoclassical growth theory (see for example Barro and Sala-i-Martin, 1995, p.172). They assume that the production function is of Cobb-Douglas type, $Y=A K^{a} H^{1-a}$, where $K$ is physical, and $H$ is human capital. Human capital, $H=h L$ can grow by improvements of its quality, while labor force $L=$ const (this corresponds to a demographically stationary economy). The result of the model is a constant growth rate of consumption, along with similar growth of physical and human capital. The growth rate of the economy is given by $r=$ $A a^{a}(1-a)^{1-a}-\delta$ with $\delta$ being the depreciation rate. The ratio of physical to human capital stays constant along the growth path, and both physical and human capital receive a constant share of output. Hence, return to capital and wage grow exponentially. This model is formally equivalent to an AK model (Barro and Salai-Martin, 1995, ch.4), which however does not produce similar results for wages, and thus cannot be used here.

Assume now a constant rate of accumulation of human capital, proportional to labor experience. Assume also that children of the next generations inherit more and more initial human capital endowment from their parents. Then an assumption about constant wages in one moment for all workers, independently on age, becomes consistent with the neoclassical growth model.

As we have assumed, firms are financed by equity, and return to capital is growing exponentially. This growth is not put directly into the price of one share, but the total number of shares is growing exponentially, while the price of one share stays constant. This assumption is purely technical, and does not correspond to new public offerings: shares bring return in shares, and we do not need to introduce money. In an economy with balanced growth, the state sector can also grow proportionally. Since bonds bring lower return than stocks, $r_{F}<r_{S}$, new bonds can be issued at a rate $r_{S}-r_{F}$ per time period. Hence, in a demographically stationary economy everything is growing at the same rate, and prices stay constant (no inflation).

\subsection{Appendix 2: Aggregation}

It can be shown that the ratio between wealth of a cohort having age $a$ at time $t+T$ and wealth of a cohort having age $a$ at time $t$ does not depend on age $a$. Recalling equation (3) it holds that for low-wealth individuals we have (here we assume that $V_{l} \equiv V_{l, 1}$ for $20<a<60$ and $V_{l} \equiv V_{l, 2}$ for $60<a<80$ ):

$$
V_{l}(a, t+T) / V_{l}(a, t)=e^{r_{S} T}, \quad \forall T \text {. }
$$


Similarly for high wealth individuals equation (2) implies

$$
V_{r}(a, t+T) / V_{r}(a, t)=e^{r_{S} T}, \quad \forall T .
$$

The individual time paths of wealth accumulation then implies that aggregate capital in the economy $K$ will grow exponentially:

$K(t+T)=\int_{0}^{80}\left(V_{l}(a, t+T)+V_{r}(a, t+T)\right) d a=e^{r_{S} T} \int_{0}^{80}\left(V_{l}(a, t)+V_{r}(a, t)\right) d a$.

The initial capital stock is given by the sum of the initial wealth holdings at $t=0$. According to our macroeconomic framework, wages grow exponentially as well and consequently the economy grows exponentially.

\subsection{Appendix 3: Properties of the Delta-Function}

The $\delta$-function was introduced by physicist Paul Dirac in 1930s, but it took about 30 years for mathematicians to develop a rigorous theory of generalized functions, which also covers this function. A good article for non-physicists about Diraks $\delta$-function is in Franckhsche Verlagshandlung (1969). A rigorous mathematical formalization can be found in Koshlyakov et al. (1964), p.679. The most interesting property of the $\delta$-function is that it allows to stress a value of a function at a particular point.

Formally, the $\delta$-function $\delta(x)$ takes the value zero in all points $x \neq 0$, but its value at $x=0$ is so high, that the integral over any interval $E$, covering $x=0$, from this function equals to one: $\int_{E} \delta(x) d x=1$.

The $\delta$-function is the weak limit ${ }^{23}$ of the so called $\delta_{n}$-sequence, which should satisfy the following properties:

a) $\int \delta_{n}(x)=1, \forall n$,

b) $\delta_{n}(-x)=\delta_{n}(x)$,

c) $\delta_{n}(x) \rightarrow \delta(x), n \rightarrow \infty$.

Such a sequence can be easily constructed in a class of continuous, infinitely differentiable functions:

$$
\delta_{n}(x)=\frac{1}{\sqrt{2 \pi} \sigma_{n}} e^{-\frac{x^{2}}{2 \sigma^{2}}} \rightarrow \delta(x),
$$

\footnotetext{
${ }^{23}$ Weak limit is a mathematical concept in functional analysis; it means that the function is defined only on its scalar products with normal functions, i.e. through the value of integrals from its products with these functions, $(\delta(x), f(x)) \equiv \int \delta(x) f(x) d x$. Thus, if we take instead of $\delta$-function an element of $\delta_{n}$-sequence with $n$ high enough, then the difference between scalar products will be small.
} 
for $\sigma_{n} \rightarrow 0$. Another sequence, $g_{n}$, is given by a set of functions of rectangular shape:

$$
g_{n}(x)=n / 2, \quad x \in[-1 / n, 1 / n], \quad g_{n}(x)=0, \quad x \notin[-1 / n, 1 / n] .
$$

Although these functions are non-differentiable, they exactly correspond to the notion of a cohort in demography, when total birth are counted over some time interval (one year, one month, etc. ). The smoother is the function $G(a)$, which is integrated with $\delta$-functions, the broader can this interval of aggregation be for one cohort, which allows to substitute approximately the $\delta$-function by the element from the $\delta$-sequence. This is exactly how we proceed when we apply the exact formula for the $\delta$-function for cohorts of finite "thinness". 


\section{References}

Abel, A.B. (2001) Will Bequests Attenuate the Predicted Meltdown in Stock Prices when Baby Boomers Retire? Review of Economics and Statistics 83(4), 589-595.

Abel, A.B.(2002) The Effects of a Baby Boom on Stock Prices and Capital Accumulation in the Presence of Social Security. NBER Working Paper 9210, Massachuetts.

Ang, A. and Maddaloni, A. (2001) Do Demographic Changes Affect Risk Premiums? Evidence from International Data. Mimeo, Columbia University, New York (N.Y.).

Atkinson, A.B. (1995) Incomes and the Welfare State. Essays on Britain and Europe. Cambridge University Press.

Barro, R. and Sala-i-Martin, X. (1995) Economic Growth. McGraw Hill.

Bakshi, G.S. and Chen, Z. (1994) Baby Boom, Population Aging, and Capital Markets? Journal of Business, 67, 165-202.

Birg, H. (2001) Die demographische Zeitwende: Der Bevölkerungsrückgang in Deutschland und Europa. Beck, München.

Börsch-Supan, A. (2002) International Comparison of Household Savings Behaviour: The German Savings Puzzle. MEA Discussion Paper Series 060002, Mannheim Research Institute for the Economics of Aging, University Mannheim, Germany.

Börsch-Supan, A. and Essig, L. (2002) Stockholdings in Germany, MEA Discussion Paper Series19-0002, Mannheim Research Institute for the Economics of Aging, University Mannheim, Germany.

Brooks, R. (2000) What Will Happen to Financial Markets When the Baby Boomers Retire? International Monetary Fund Working Paper WP/00/18, Washington, D.C.

Constantinides, G.M., Donaldson, J.B. and Mehra, R. (2000) Junior Can't Borrow: A New Pespective on the Equity Premium Puzzle, Quarterly Journal of Economics 117, 269-296.

Federal Statistical Office, (1995) Capital Taxes Statistics (Vermögensteuerstatistik), Wiesbaden. 
Federal Statistical Office, (1998) Einkommens- und Verbrauchsstichprobe (EVS, Income and Expenditure Survey), Fachserie 15, Heft 4, Wiesbaden.

Franckhsche Verlagshandlung (1969), Lexikon der Physik, 3. Auflage Bd. 2 (3), Stuttgart.

Gollier, C. (2001) Wealth Inequality and Asset Pricing, Review of Economic Studies 68, 181-203.

Jagannathan, R. and Kocherlakota, N.R. (1996) Why Should Older People Invest Less in Stocks Than Younger People? Quarterly Review, Federal Reserve Bank of Minneapolis.

Kapteyn, A. and Panis, C. (2002) The Size and Composition of Wealth Holdings in the United States, Italy, and the Netherlands, mimeo, Labor and Population Program, RAND.

Koshlyakov, N., Smirnov, M. and Gliner, E. (1964) Differential equations of mathematical physics. North Holland.

Lüth, E. (2001) Private Intergenerational Transfers and Population Aging. The German Case. Phyisca-Verlag, Germany.

Maki, D.M. and Palumbo, M.G. (2001) Disentangling the Wealth Effect: A Cohort Analysis of Household Saving in the 1990s. Federal Reserve Board, Finance and Economics Discussion Series No. 2001-21, Washington, D.C.

Mankiw, G.N. and Weil, D. (1989) The Baby Boom, the Baby Bust, and the Housing Market, Regional Science and Urban Economics 19, 235-258.

Poterba, J.M. (1998) Population Age Structure and Asset Returns: An Empirical Investigation. NBER Working Paper Series No. 6774, Cambridge, MA.

Poterba, J.M. (2001) Demographic Structure and Asset Returns, Review of Economics and Statistics, 83, 565-584.

Rodriguez, S.B., Diaz-Gimenez, J., Quadrini, V. and Rios-Rull, J.V. (2002) Updated Facts on the U.S. Distributions of Earnings, Income, and Wealth. Quarterly Review, Federal Reserve Bank of Minneapolis, Minneapolis, MI.

Schieber, S.J., Shoven, J.B. (1994) The Consequences of Population Aging on Private Pension Fund Saving and Asset Markets. NBER Working Paper No. 4665. 
Szydlik, M. (2002) Familie-Lebenslauf-Ungleichheit. Aus Politik und Zeitgeschichte B 22-23, 7-9.

Yoo, P.S. (1994) Age distributions and returns of finanical assets. Working Paper 1994-002A, The Federal Reserve Bank of St. Louis.

Wolff, E.N. (1995) Top heavy: A study of the increasing inequality of wealth in America. Twentieth Century Fund Press, New York. 
Figure 1.a

num ber of births, FRG

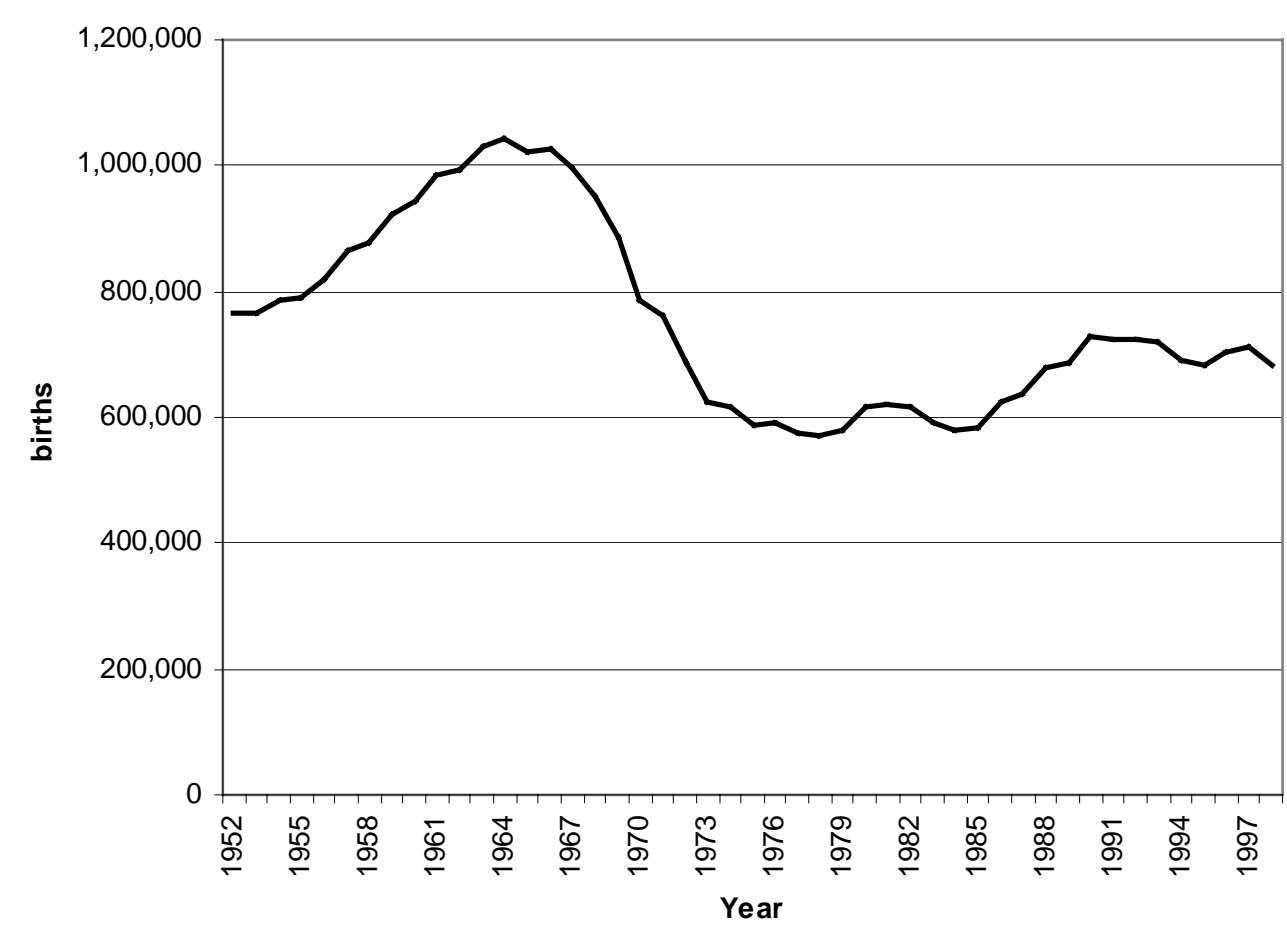

Figure 1.b

Population age structure (\%), FRG

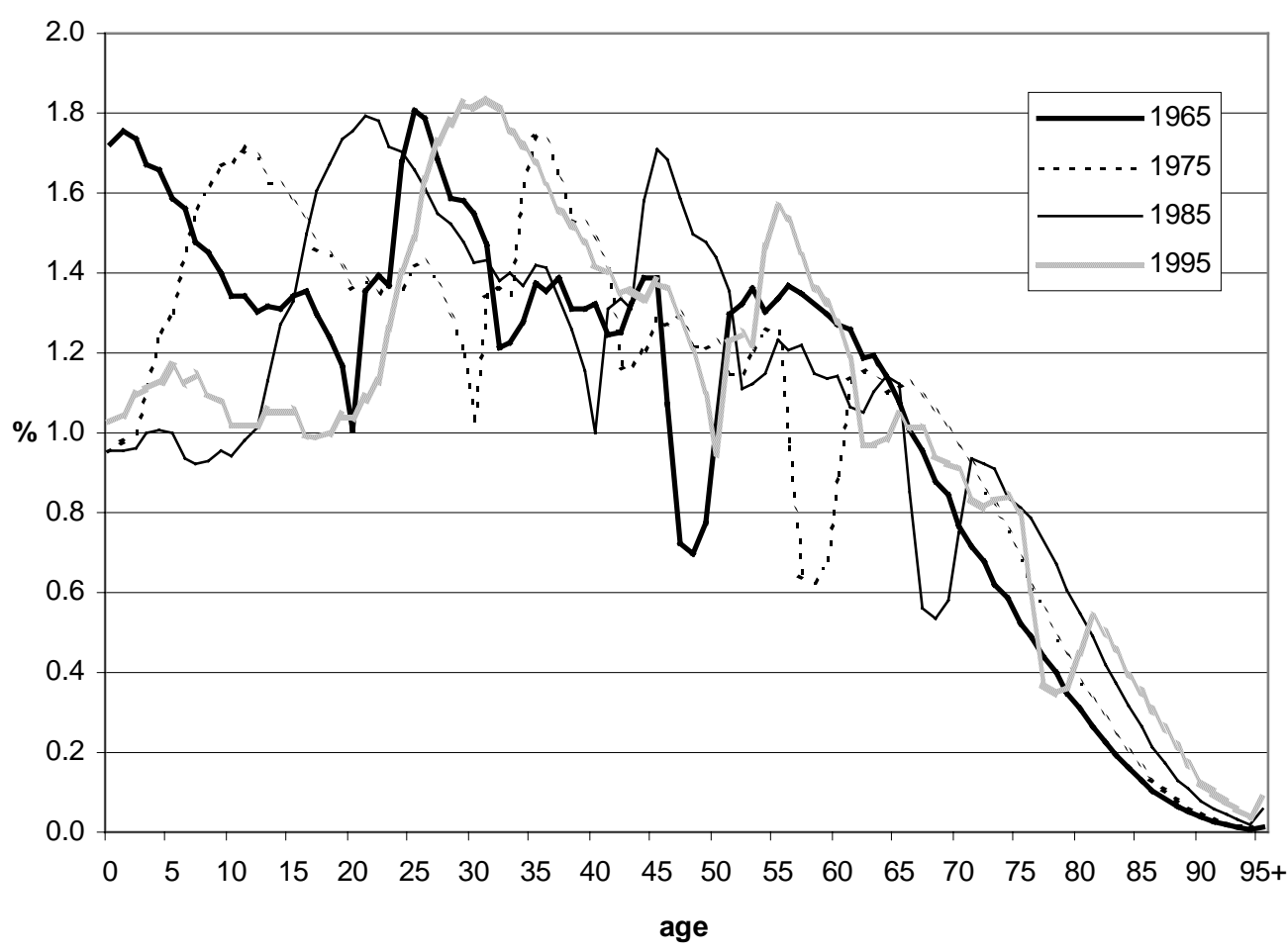


Bond and stock prices, wealth homogeneity across ages of high-wealth individuals, $r$ _S $=0.04$

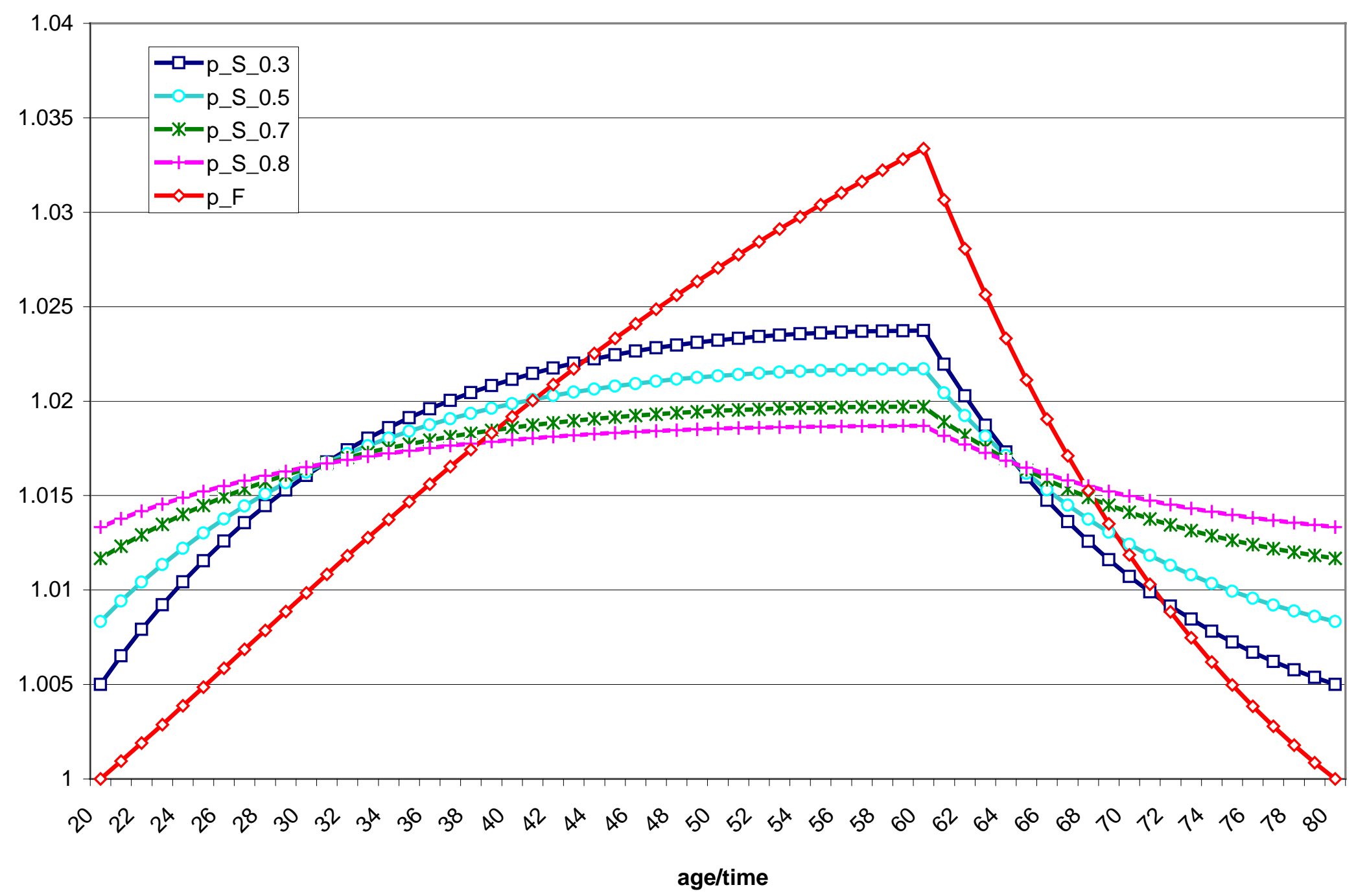


Bond and stock prices, wealth homogeneity across ages of high-wealth individuals, $r \_S=0.08$

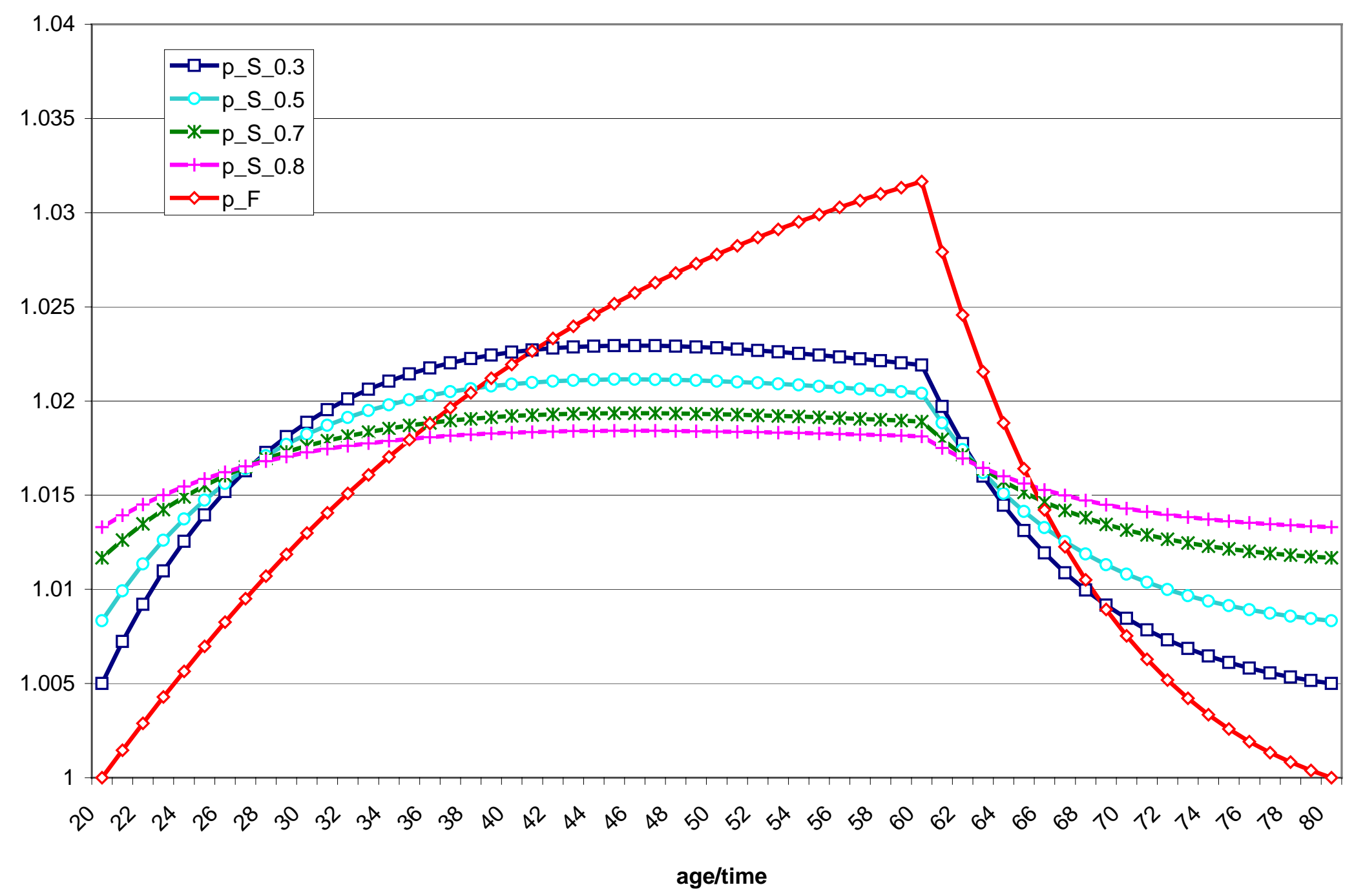


Stock prices, wealth heterogeneity across ages of high-wealth individuals, r_S=0.04

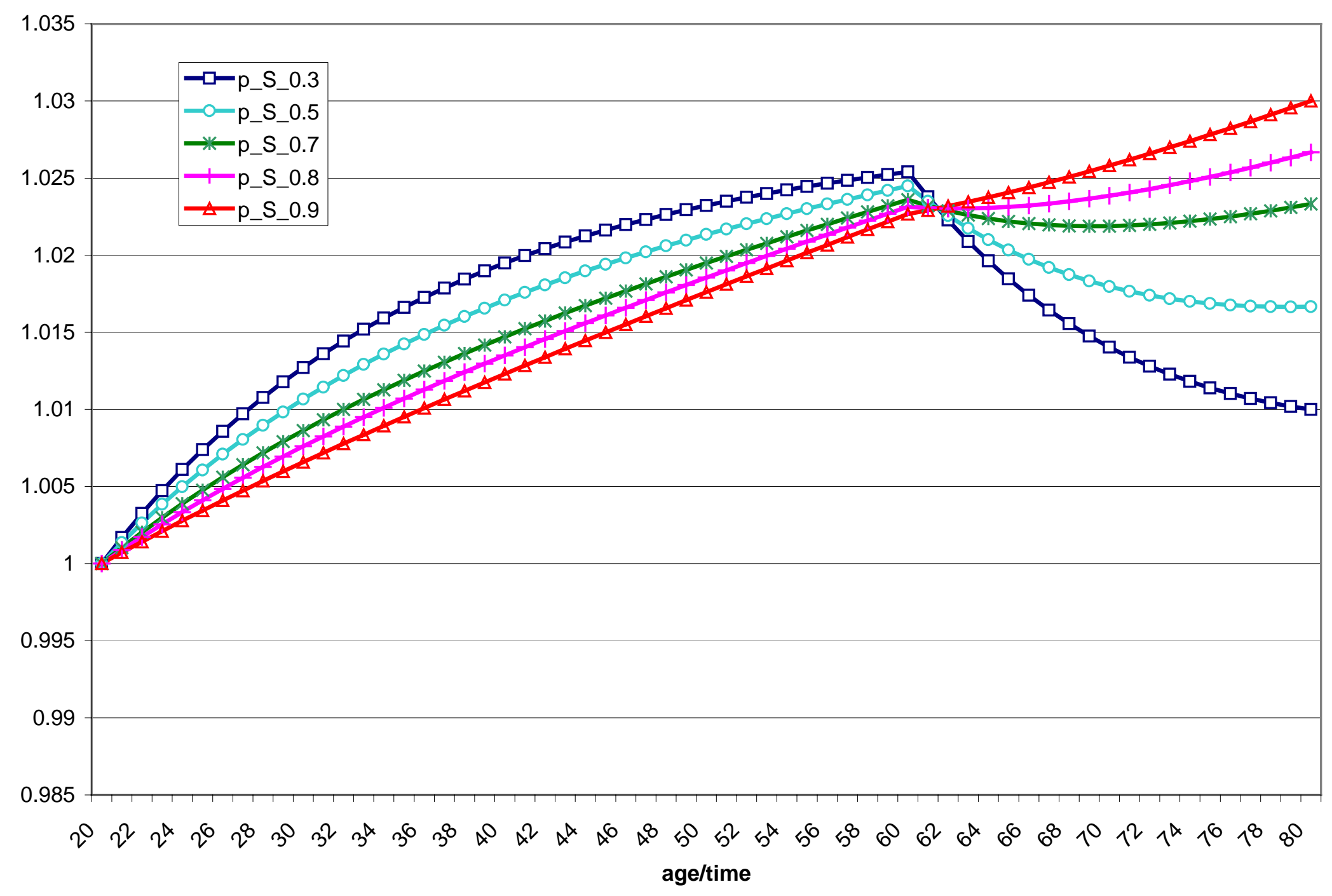

